Marquette University

e-Publications@Marquette

Chemistry Faculty Research and Publications

Chemistry, Department of

6-1-1997

\title{
The Electrochemical Oxidation of Organic Selenides and Selenoxides
}

Michael D. Ryan

Marquette University, michael.ryan@marquette.edu

Jiyi Yau

Marquette University

Michael Hack

Marquette University

Published version. Journal of the Electrochemical Society, Vol. 144, No. 6 (June 1997): 1952-1957.

DOI. (C) 1997 Electrochemical Society. Used with permission.

Shareable Link. Provided by the Springer Nature SharedIt content-sharing initiative. 


\title{
The Electrochemical Oxidation of Organic Selenides and Selenoxides
}

\author{
Michael D. Ryan," Jiyi Yau, and Michael Hack \\ Department of Chemistry, Marquette University, Milwaukee, Wisconsin 53201, USA
}

\begin{abstract}
The electrochemical oxidation of alkyl and aryl selenides was investigated in acetonitrile. The oxidation of diphenyl selenide and di(4-methylphenyl) selenide led primarily to the formation of their respective selenoxides, which were identified by exbaustive coulometric oxidation and ${ }^{1} \mathrm{H}$ and ${ }^{13} \mathrm{C}$ analysis of the products. The selenoxide itself was not observed in the cyclic voltammetry of the selenide for two reasons: first, the protonation of the selenoxide by the acid formed from the reaction of water with the cation radical and second, the formation of a selenoxide hydrate. The formation of the hydrate with diphenyl selenoxide was verified by isolation of the dimethoxy derivative. In addition to the selenoxide, selerionium compourids, formed by the coupling of the oxidized material, were also observed. The alkyl selenides were generally oxidized at a lower potential than the aryl selenides. This trend is different from the sulfur aralogues, where the aryl sulfides are easier to oxidize than their alkyl counterparts. As a result, the difference in their redox potentials is relatively small. These differences may occur because the oxidation of aryl sulfides is more likely to take place on the aromatic ring, which leads to a greater yield of the coupled products (about $100 \%$ ) when compared to the selenide analogue.
\end{abstract}

\section{Introduction}

The electrochemical oxidation of sulfur and selenium compounds generally leads to organic radicals which are ofter quite reactive and can initiate a wide variety of chemical reactions. Some of the possible pathways for the decay of these radicals are summarized in Fig. 1. Pathway 1 (formation of the dimeric dication) has beer observed in the oxidation of dialkyl sulfides. ${ }^{2}$ In the presence of water, the dimer formed from dimethyl sulfide will decompose to form methanesulfonic acid and carbon monoxide. ${ }^{2}$ Steric hindrance at the sulfur atom will inhibit the dimerization reaction, allowing other processes such as deprotonation to dominate. 'In cyclic dithia ard diselena compounds, the coupling is intramolecular and the product is quite stable ${ }^{3-6}$ for example, dithiacyclooctane undergoes a reversible two-electron oxidation to the dication, with a transannular S-S bond, ${ }^{3,4}$ Similar voltammetry was

* Electrochenical Society Active Member. observed for diselenacyclooctane ${ }^{5}$ Fujihara et al..$^{5.7}$ also examined acyclic selenides using cyclic voltammetry.

The oxidation of aryl chalcogenides generally leads to coupling via a C-E bond (where $\mathrm{E}$ represents $\mathrm{S}$ or $\mathrm{Se}$ ) (pathway 2, Fig. 1). The sulfonium dimer was observed with yields between 57 and 7 1 \% for a variety of alkyl aryl and diaryl sulfides. ${ }^{*} 30$ The selenonium salt was also postulated to be formed as a minor product in the oxidation of diphenyl seleride." The electrochemical oxidation of diphenyl ether leads to extensive polymerization, probably via oxonium ions. ${ }^{12}$ If the oxidation is carried out in the presence of benzene, the triphenyloxomium salt is formed. ${ }^{12}$ Pathway 3 is the dominant reaction if the solvent and electrolyte are not rigorously dried. In the presence of water, dialkyl sulfides, methyl phenyl sulfide, and benzyl phenyl sulfide are oxidized by a two-electron reaction to sulfoxides. ${ }^{1,2}$ Diphenyl selenide is oxidized to diphenyl selenoxide in high yield if water is present. ${ }^{1}$ Oxidation of benzyl phenyl selenide under the same conditions also 


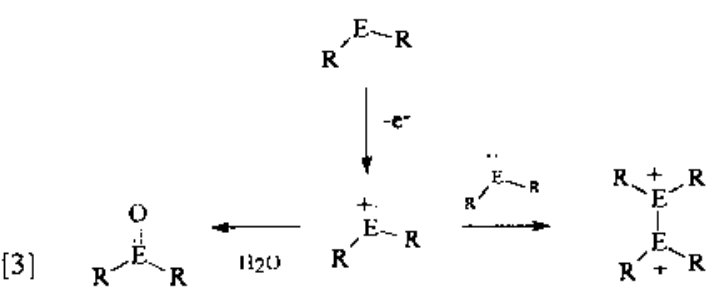

$$
\left.\right|_{R^{\prime}} ^{R^{\prime} E-R R}
$$

Fig. I. Fate of the $R_{2} E^{+*}$ radical cation formed by the oxidation of $R_{2} E . E=S$ or $S e$ atom. $R=$ alkyl or aryl group.

leads initially to the selenoxide, which rapidly rearranges to a selenenic ester." Cleavage of this ester forms benzaldehyde and, ultimately, diphenyl diselenide. ${ }^{14}$ High yields of diaryl diselenides were also observed for alkyl aryl selenides, where the alkyl group was varied from ethyl to hexyl:-5

\section{Experimental}

Chemicals..--Spectrograde acetonitrile and 2,6-di- $t$ butylpyridine (Aldrich Chemical Co.) were used without further purification. Anhydrous sodium perchlorate was obtained from G.F. Smith Chemical Co and used as obtained. 1,1-Selenobisbenzene (diphenyl selenide, I'h, Se) was obtained from Alfa Chemical Co. 1, $1^{\prime}$ Selenobis(4-methylbenzene) [di(4-methylphenyl) selenide, $\mathrm{Tol}_{2} \mathrm{Se}$ ] was synthesized by a literature procedure. ${ }^{15} 1,1^{\prime}-$ Seleninylbisbenzene (diphenyl selenuxide, $\mathrm{Ph}_{2} \mathrm{SeO}$ ) and 1,1'-seleninylbis(4-methylbenzene) [di(4-methylphenyl) selenoxide, Tol ${ }_{2} \mathrm{SeO}$ were synthesized by $\mathrm{N}$-chlorosuccinimide oxication. ${ }^{15}$ Dimethoxyd:phenyl seleniam was made by the method of Paetzold and Lindner." Selenane and 1,4-disclenane were synthesized by literature procedures.

Equipment,-Proton nuclear magnetic resonance (NMR) spectra were obtained on a Varian A-foA instrument. The "C NMR spectra were recorded on a JEOL/JNM-FX60Q FT-NMR. Deuterated chloroform was used for all the NMR spectra. An EG\&G Princeton Applicd Research Corp. Model $174 \Lambda$ potentiostat was used for the cyclic voltammetric data. The reference electrode was a saturated calomel electrode ( $\mathrm{SCE}$ ), the auxiliary electrude was platinum, as was the working electrode (area $0.44 \mathrm{~cm}^{\prime \prime}$ ). The reference electrode was separated from the sample solution by a salt bridge. $\Lambda$ homemade potentiostat with an EG\&G Model 379 digital coulometer was used for the coulometric experimerits. A carbon electrode was used for the coulometric working electrode.

Procedures.-All solutions were deacrated with dinitrogen prior to obtaining the cyelic voltammograms. Digisim 2.0 (Bioanalytical Systems, W. Lafayette, IN) was used to simulate the oxidation of diphenyl selenide via pathways 2 and 3 in Fig. 1. The elementary steps of the simulation are distinguished as electron transfer reaction $[\mathrm{E}$ No.l chemical reaction [R No.]

$$
\begin{aligned}
& \mathrm{I}^{\mathrm{T}} \mathrm{h}_{2} \mathrm{Se}=\mathrm{I}^{\prime} \mathrm{h}_{2} \mathrm{Se}^{-} \cdot e^{-} \\
& \mathrm{Ph}_{2} \mathrm{Se}^{+}+\mathrm{Ph}_{2} \mathrm{Se} \rightarrow \mathrm{Ph}-\mathrm{Se}-\mathrm{Ph}-\mathrm{Se}\left(\mathrm{I}^{\prime}{ }_{2}\right)_{2}+\mathrm{H}^{+} \\
& \mathrm{Ph}-\mathrm{Se}-\mathrm{I} h-\mathrm{Se}(\mathrm{Ph})_{2}{ }^{\cdot}=\mathrm{Ph}-\mathrm{Se}-\mathrm{Ph}-{ }^{-S e}(\mathrm{Ph})_{2}-e^{-} \\
& \mathrm{Ph}_{2} \mathrm{Se}^{\prime}+\mathrm{H}_{2} \mathrm{O} \rightarrow \mathrm{Ph}_{2} \mathrm{Se}(\mathrm{OH}) \cdot+\mathrm{H}^{\prime} \\
& \mathrm{Ph}_{2} \mathrm{Se}(\mathrm{OH}), \rightleftharpoons \mathrm{Ph}_{2} \mathrm{Se}(\mathrm{OH})^{2}-e \\
& \mathrm{Ph}_{-\mathrm{Se}}(\mathrm{OH})^{\circ}-\mathrm{H}_{2} \mathrm{O} \rightarrow \mathrm{Ph}_{2} \mathrm{Se}(\mathrm{OH})_{2}+\mathrm{H}
\end{aligned}
$$

Reaction E2 leads to the product of pathway 2, while R3 leads to the hydrate of the selenoxide, postulated in pathway 3 (see text below for the rationale for this product). The product of reaction E2 could be oxidized in a second wave, E4, and this was also included in the simulation

$\mathrm{Ph}-\mathrm{Se}-\mathrm{Ph}-\mathrm{Se}(\mathrm{Ph})_{2}-\mathrm{H}_{2} \mathrm{O}$

$$
\rightarrow \mathrm{Ph}-\mathrm{SeO}-\mathrm{I}^{\prime} \mathrm{h}-\mathrm{Sc}^{+}-\mathrm{I}^{\prime} \mathrm{h}_{\mathrm{z}}-2 e-2 \mathrm{H}
$$

The standard redox potentials of reactions El-E4 ( $E_{\text {: }}^{c}$ through $E_{4}^{*}$, respectively) and the standard heterogeneous electron transfer rates of those reactions ( $k_{\mathrm{s} \text { : }}$ through $k_{\mathrm{s}: \text { : }}$ respectively) were chosen so that the waves were irreversible in shape, and the peak occurred at the same potentials that were observed in the experimental data. The values of the homogeneous rate constants (for reactions R1 through $R 3, k_{11}$ through $k_{1 \hat{s}}$, respectively) were chosen so trat the shape of the wave dependec only upon the ratio of the rate constants and not on their specific values [the reaction was always in the "pure kinetic" (KI') zone]. The electron transfer coefficients, $\alpha$, for each electron transfer were then varied in order to obtain the best fit to the experimental data.

Where noted, the current due to the second peak was corrected for the current decay of the first peak ("Cottrell decay"). The current decay was ealculated using the procedure of Polcyn and Shain ${ }^{25}$

$$
i_{i}=\frac{a}{\sqrt{E-E_{2}}}
$$

where $a$ and $E_{x}$ are constants determined from the best. fit of the current between 50 and $150 \mathrm{mV}$ past the peak, and $i_{1}$ is the extrapolated current at a potential, $E$

Controlled potential electrolysis was carried out in acetonitrile with $0.10 \mathrm{M} \mathrm{NaClO}$. After electrolysis, the solvent was removed under reduced pressure. The oxidation product was separated from the electrolyte by addition of chlorotorm and water: The chloroform phase was separated, dred with magnesium sulfate, and the coulometry product was obtained by removal of the solvent under reduced pressure. The isolated product was then dissolved in choroform-d: for ${ }^{1} \mathrm{H}$ and ${ }^{19} \mathrm{C}$ N.IR analysis.

\section{Results and Discussion}

Electrochemistry of aryl selenides and selenoxides. The cyclic voltammetry of $\mathrm{Ph}$. Se in acetonitrile has been previously reported. ${ }^{1:}$ Three peaks were observed in the uxidation process. The first peak occurred at $-1.41 \mathrm{~V} z \mathrm{~s}$. SCE at $100 \mathrm{mV} / \mathrm{s}$ [Fig. 2 (solid line)]. The second and third peaks, which were considerably smaller, occurred at +1.62 and $+1.81 \mathrm{~V}$, respectively. The overall reaction for the first peak could be written as

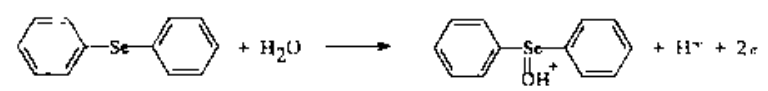

Scheme 1.

The second and third peaks were reported to be due to the formation of dimeric species via the following mechanism

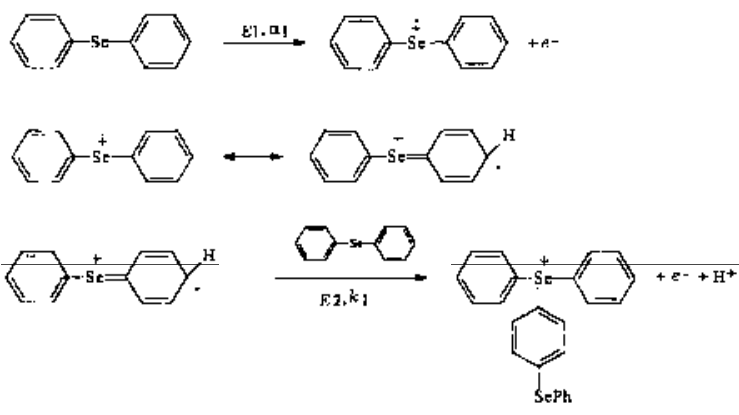

Scheme 2.

The only product that was unambiguously identified in the proton NMR was the selenoxide product, I'h, SeO These same results were confirmed in our laboratory. The proton NMR spectrum of the electrolyzed product was 
Toble 1. ' ${ }^{3} \mathrm{C}$ NMR spectra of seleno-, seleninyl-, and selenonylbisbenzenes.

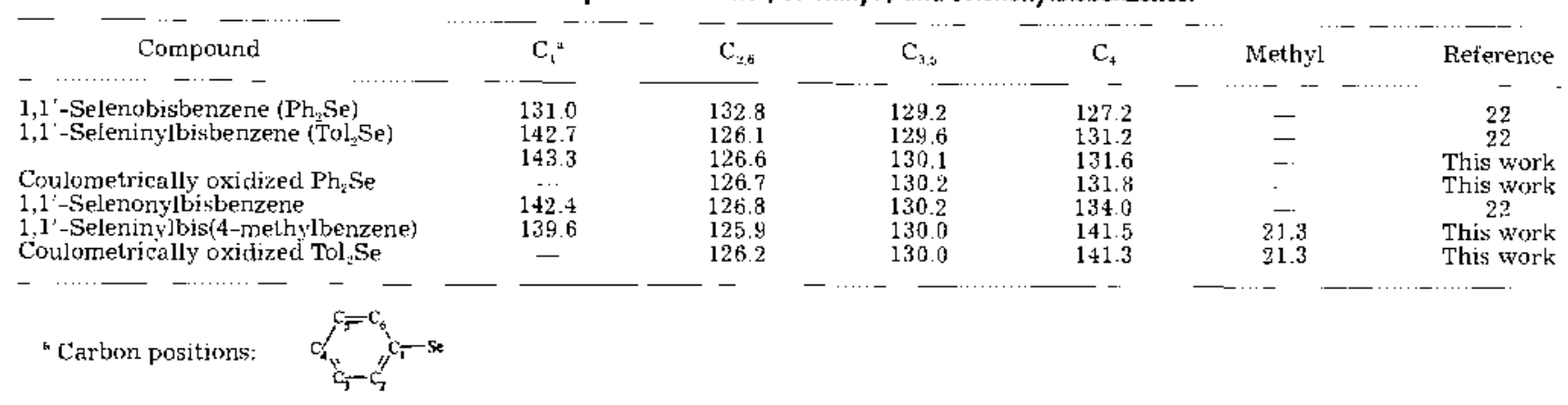

consistent with material prepared by chemical synthesis (resonances at 7.40 and $7.65 \mathrm{ppm}$ ). ${ }^{21}$ The ${ }^{13} \mathrm{C}$ NMR spectrum also confirmed the formation of the selenoxide (Table I), and was significantly different from the starting material and the more oxidized selenone product $\left(\mathrm{Ph}_{2} \mathrm{SeO}_{2}, 1,1^{\prime}\right.$-selenonylbisbenzene)

The two different products (coupling vs. selenoxide) are formed due to the two different fates of the initial radical species. Because the intensity of the second peak, as measured from the Cottrell decay of the first peak (as described in the Experimental section), did not depend upon the concentration of the starting material, the rate-limiting step for the coupling reaction must be a first-order process such as the loss of a proton, after the attack of the seienide to form the selenonium species $\left(k_{1}\right)$. If addition of water occurs first $\left(k_{2}\right)$, the selenoxide is formed

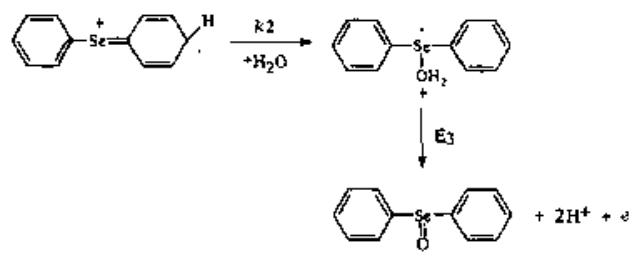

There was no decrease in the current functions for the second peak up to $500 \mathrm{mV} / \mathrm{s}$, indicating that the reaction rate $\left(k_{1}\right)$ must be greater than $200 \mathrm{~s}$ : ${ }^{3}$ Digital simulation for the anodic scan using this mechanism is shown in Fig. 2 (dotted line) for a $k_{1} / k_{2}$ ratio of 0.30 . Addition of water caused only minor changes in the voltammograms. In the presence of $125 \mathrm{mM}$ water, the third peak disappeared, and there was a small (about $20 \%$ ) decrease in the ratio of the second peak current, $i_{p 12}$, to the first $\left(i_{p t 2}\right.$ was measured

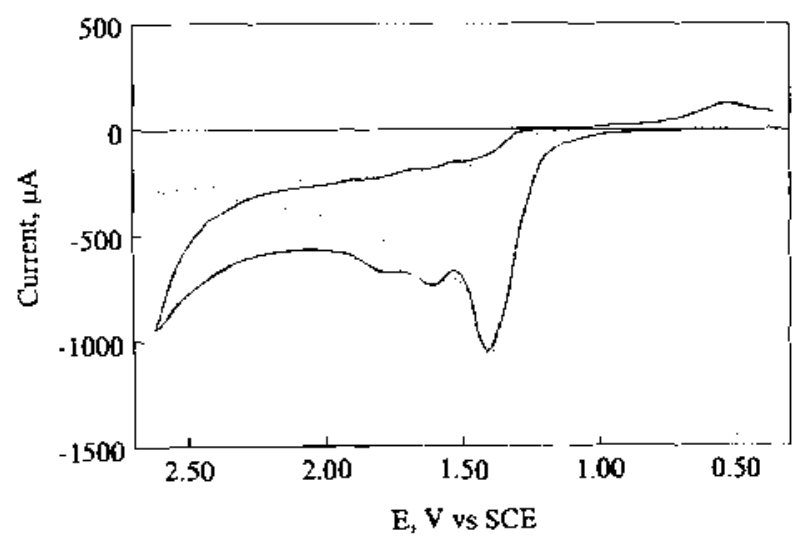

Fig. 2. Cyclic voltammetry of $4.0 \mathrm{mM} 1,1^{\prime}$-selenobisbenzene in acetonitrile at a platinum electrode, $0.10 \mathrm{M}$ sodium perchlorate, scan rate $100 \mathrm{mV} / \mathrm{s}$. $(-1)$ experimental data and $(\cdots \cdot)$ digital simulation of Schemes $i$ and 2 , where $k_{1} / k_{2}=0.30$. Simulation parameters: $E_{1}=+1.42 \mathrm{~V}, \alpha_{1}=0.35, k_{\mathrm{s}, 1}=10^{-4} \mathrm{~cm} / \mathrm{s} ; E_{2}=+1.00 \mathrm{~V}$, $\alpha_{2}=0.50, k_{2}=10^{-4} \mathrm{~cm} / \mathrm{s} ; E_{3}=+0.80, \alpha_{3}=0.50, k_{33}=10^{-4} \mathrm{~cm} / \mathrm{s}$, $k_{1}=300 \mathrm{~s}^{-1}$, and $k_{2}=1000 \mathrm{~s}^{-1}$. from the Cottrell decay of the first wave). One can rationalize the small changes in the second peak if one assumes that the loss of $\mathrm{H}^{\prime}$ in the third line of Scheme 2 requires the presence of a good base such as water. As a result, both the dimerization and water reaction $\left(k_{1}\right.$ and $\left.k_{2}\right)$ are dependent upon the concentration of water.

Only one irreversible oxidation peak at $+1.29 \mathrm{~V}$ was observed for the 4-methyl analogue of $\mathrm{Ph}_{2} \mathrm{Se}\left(\mathrm{Tol}_{2} \mathrm{Se}\right)$ because the 4-position was blocked. The peak was found to be a diffusion-controlled two-electron peak, as was the first peak of $\mathrm{Ph}_{2} \mathrm{Se}$. The product of the oxidation was verified $t o$ be $\mathrm{Tol}_{2} \mathrm{SeO}$, by ' $\mathrm{H}$ NMR $[\delta=2.35(\mathrm{~s}, 6 \mathrm{H}$ ), 7.25 (d, $4 \mathrm{H}, \mathrm{J}=8 \mathrm{~Hz}$ ), $7.55(\mathrm{~d}, 4 \mathrm{H}, \mathrm{J}=8 \mathrm{~Hz}$ ), compared with the literature values of $\delta=2.39,7.27,7.57^{21}$ ) and ${ }^{13} \mathrm{C} \mathrm{NMR}$ (Table I).

Because selenoxides are the product of the oxidation reaction, the electrochemical oxidation of $\mathrm{Ph}_{2} \mathrm{SeO}$ and $\mathrm{Tol}_{2} \mathrm{SeO}$ was also investigated. A single oxidation peak at $+1.99 \mathrm{~V}$ (Table II) was observed for $\mathrm{Ph}_{2} \mathrm{SeO}$. The peak current function for $\mathrm{Ph}_{2} \mathrm{SeO}$ was less than half of $\mathrm{Ph}_{2} \mathrm{Se}$, and the peak was considerably broader. The lower current function for $\mathrm{Ph}_{2} \mathrm{SeO}$ was consistent with the results previously obtained for the sulfoxide analogue; 1,1'-sulfinylbisbenzene, which was oxidized by an overall one-electron process. ${ }^{m *}$ Similar behavior was observed for $\mathrm{Tol}_{2} \mathrm{SeO}$ (Fig. 3, solid line).

A close examination of the cyclic voltammograms of $\mathrm{Ph}_{2}$ Se showed that neither the second nor the third peak corresponded to $\mathrm{Ph}_{z} \mathrm{SeO}$, even though it was the primary product of the reaction. Similarly, no peak due to the selenoxide was detected in the voltammetry of Tol $2 \mathrm{Se}$. One possible reason for the absence of the peak may be that the conjugate acid of $\mathrm{Ph}_{2} \mathrm{SeO}$, the product formed in the presence of acid, may be electroinactive. In order to investigate this possibility, the voltammetry of $\mathrm{Tol}_{2} \mathrm{SeO}$ in the presence of strong acids was investigated. As can be seen in Fig. 3 , the peak for the selenoxide decreased substantially in the presence of perchloric acid. With an excess of perchloric acid, no peak was observed for the selenoxide due to the protonation of the substrate. The following scheme can then be written for the voltammetry of $\mathrm{Tol}_{2} \mathrm{SeO}$ in the presence of strong acids

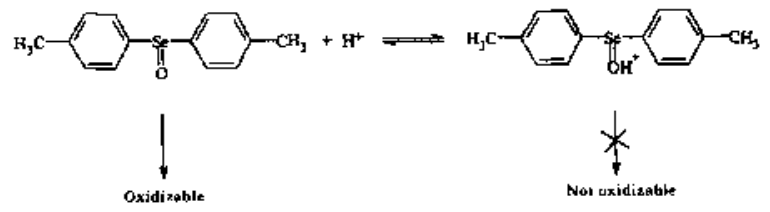

Similar behavior was also observed for $\mathrm{Ph}_{2} \mathrm{SeO}$. The protonation was reversible and the peak for the selenoxide reappeared with the addition of a nonnucleophilic base, 2,6-di-t-butyl pyridine (Fig. 4). Therefore, if the solution were basic to neutral, the selenoxide peak should be observed.

This behavior is in sharp contrast to the behavior of the corresponding sulfoxide. Addition of strong acids to diphenyl sulfoxide has no effect on its oxidation peak, and there was no evidence for the protonation of this species. ${ }^{24}$ These results are consistent with the measured aqueous 
Table II. Cyclic voltammelry of alkyl and aryl selenides and selenoxides.

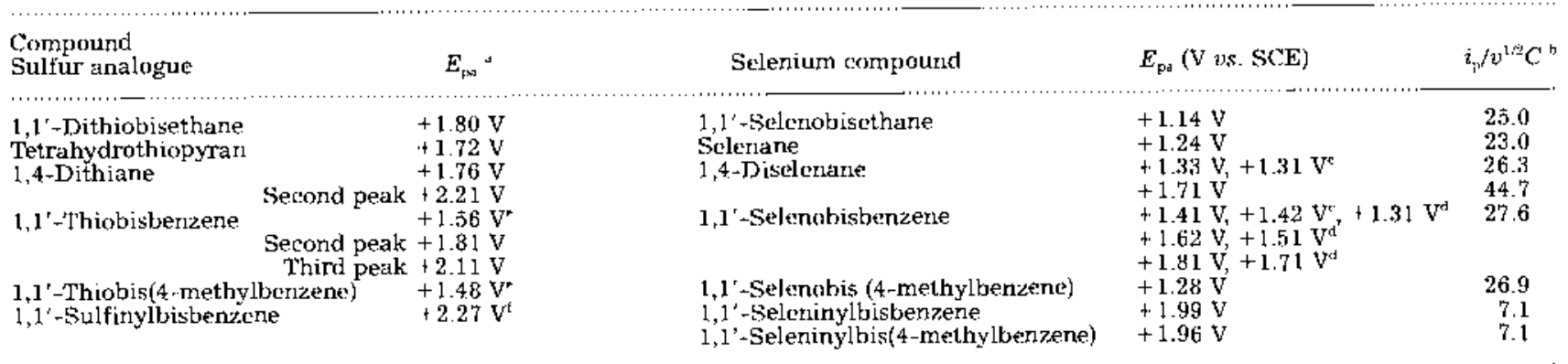

? v vs. SCE, ReL. 2 ,

$\left.\mu \mathrm{A} /(\mathrm{V} / \mathrm{s})^{\mathrm{v}} \mathrm{im} M\right)$.

5 Ref. 5 .

Ref. 24.

Ref. $2 \vec{a}$.

${ }^{f}$ Ref. 24 .

pKa values of sulfoxides and selenoxides. The selenoxide, $\mathrm{Ph}_{2} \mathrm{SeO}$, is a significantly stronger base $\left(\mathrm{p} K_{\mathrm{a}} 0.35\right)$ than the corresponding sulfoxide ( $\left.K_{\mathrm{a}}-3.19\right)^{36,37}$ leading to the different voltammetric behavior in the presence of strong acids.

The oxidation of $\mathrm{Ph}_{2}$ Se was repeated in the presence of various concentrations of 2,6 -di-t-butyl pyridine. No new peaks were observed in the voltammograms, even with a twofold excess of base (Fig. 5). The first and second peaks were unaffected by the presence of the base, but the third peak disappeared at high concentrations. This latter effect was not investigated. The results for the oxidation of $\mathrm{Tol}_{2} \mathrm{Se}$ in the presence of 2,6-di-t-butyl pyridine was identical to $\mathrm{Ph}_{2} \mathrm{Se}$ if the ratio of the base/selenide was less than unity. When this ratio is greater than 1 , a peak due to $\mathrm{Tol}_{2} \mathrm{SeO}$ could be clearly observed (Fig. 6, dashed line). The dotted line in Fig. 6 was obtained by adding the voltammogram for $2 \mathrm{mM} \mathrm{Tol}_{2} \mathrm{SeO}$ to the original voltammogram of Tol $\mathrm{T}_{2} \mathrm{Se}$. The current due to the selenoxide corresponded closely to what one would expect for the complete conversion of the sclenide to the selenoxide.

While the ultimate product in both cases was the selenoxide, it appears that, at least for $\mathrm{Ph}_{2} \mathrm{Se}$, an electroinactive intermediate is formed. Such an intermediate, the hydrate of the selenoxide, has been postulated by Sharpless et al. ${ }^{2 B}$ to explain their kinetic data on the reaction of peroxide oxidized selenides with olefins. The hydrate of organotellurium(IV) and organoselenium(IV) has also been shown to have important kinetic implications with regard to photodynamic and other oxidative

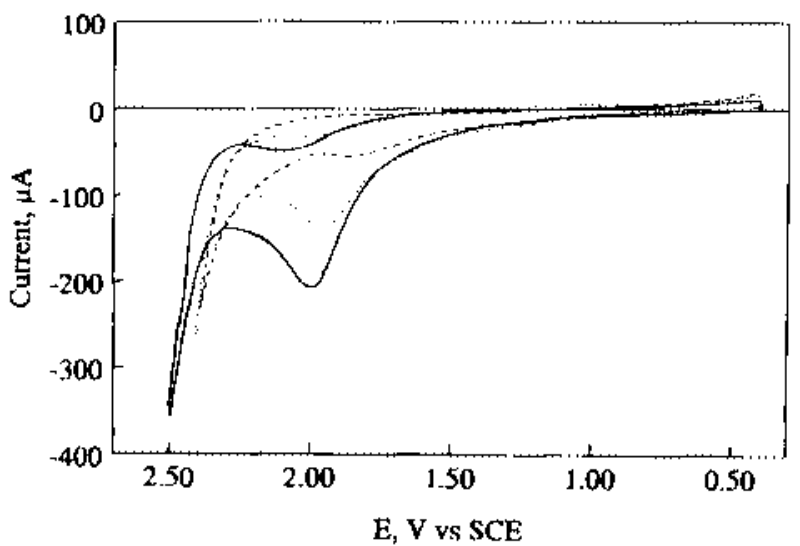

Fig. 3. Cyclic voltommerry of $4.0 \mathrm{mM} \mathrm{1,1'-seleninylbis}(4-$ melhy) benzene) in ocetonitrile at a platinum electrode, $0.10 \mathrm{M}$ sodium percholorate, scan rate $100 \mathrm{mV} / \mathrm{s}:(-10,\{\cdots) 2$, and $(---1) 4 \mathrm{mM}$ per. chloric acid. chemotherapy. ${ }^{29}$ Therefore, based on the voltammetric and coulometric data, the following oxidation mechanism can be proposed

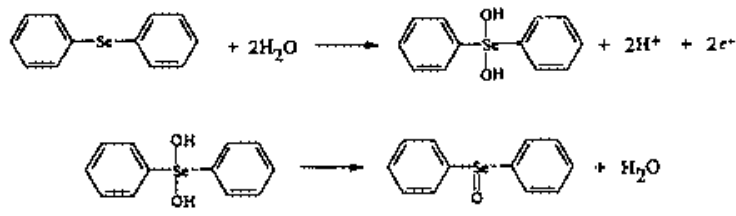

The hydrate is very unstable and is known to decompose in the presence of drying agents such as magnesium sulfate, ${ }^{2 n}$ which was used in the isolation of the coulometric product in both our work (see Experimental section) and in previous work. ${ }^{11}$ In order to identify the presence of the hydrate, the intermediate must be trapped immediately after electrolysis. The electrolysis of $\mathrm{Ph}_{2}$ Se was repeated, and after the current had decayed to the background, a twofold excess of trimethyl oxonium tetrafluoroborate was added to the solution in order to form the more stable dimethoxydiphenyl selenium

$$
\begin{aligned}
\mathrm{Ph}-\mathrm{Se}(\mathrm{OH})_{2}-\mathrm{Ph} & +2\left(\mathrm{CH}_{3}\right)_{3} \mathrm{O}^{+} \mathrm{BF}_{4}^{-} \\
& \rightarrow \mathrm{Ph}-\mathrm{Se}\left(\mathrm{OCH}_{3}\right)_{2}-\mathrm{Ph}+2 \mathrm{HBF}_{4}+2 \mathrm{CH}_{3} \mathrm{OCH}_{3}
\end{aligned}
$$

The solvent was removed again under reduced pressure, and organic material was dissolved in chloroform- $\mathrm{d}_{1}$ in order to isolate the expected product, dimethoxydiphenyl

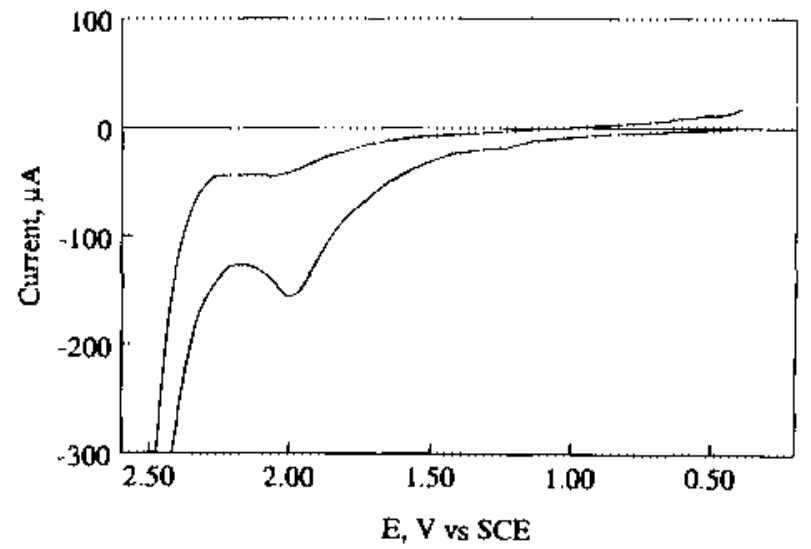

Fig. 4. Cyclic voltrammetry of $4.0 \mathrm{mM} 1,1^{\prime}$-seleninylbis $\{4$-methylbenzenel in acetonitrite at a platinum electrode affer addition of $4.0 \mathrm{mM}$ perchloric acid and $4.0 \mathrm{mM} 2,6$-di+- -butylpyridine. Scan rate $100 \mathrm{mV} / \mathrm{s}, 0.10 \mathrm{M}$ sodium perchlorole. 


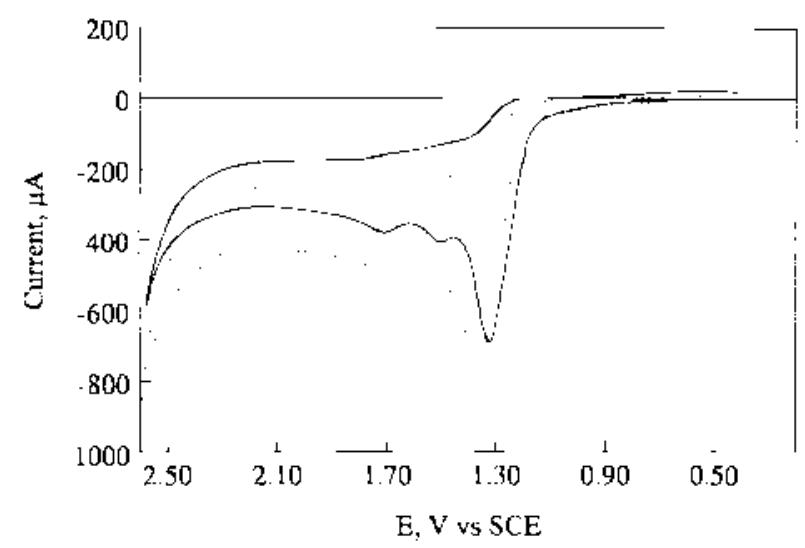

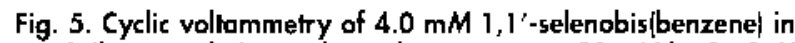
acetonitrile at a platinum electrade, scan rate $100 \mathrm{mV} / \mathrm{s}, 0.10 \mathrm{M}$ sodium perchlorate: $(-10 \mathrm{mM} 2,6$-di-tbutyl pyridine and $(\cdots)$ $8.0 \mathrm{mM} 2,6$-di-rbulyl pyridine.

sclenium. The methoxy peak was observed in both the $\cdot \mathrm{H}$ and ${ }^{\circ} \mathrm{C}$ NMR ( $\delta \quad 3.5$ and $159.0 \mathrm{ppm}$, respectively), which corresponded closely to the literature values for that resonance in the ${ }^{1} \mathrm{H}$ NMR spectrum ${ }^{3:}$ and the expected ${ }^{13} \mathrm{C}$ NMR resonante.

Cyclic woltammetry of alkyt selenides. For comparison purposes, the cyclic voltammetry of several alkyl selenides was obtained. The results are summarized in Table II. The peak current functions $\left(i, v^{1 \cdots} \mathrm{C}\right.$, where $v$ is the scan rate and $C$ the bulk concentration of the selenide) for the alkyl selenides were nearly the same as the aryl selenides, indicating that the oxidation still took place via a two-electron process, probably leading to the selenoxide. The alkyl selenides were generally oxidized at lower potentials than their sulfide analogues. For example, the oxidation poterntial of $1,1^{\prime}$-thiobis(ethane) was $660 \mathrm{mV}$ higher than the one of the selenium aralogue, $1,1^{\prime}$-selenobis(ethane). For the disubstituted rings, each peak potential was about $500 \mathrm{mV}$ lower in the selenide than the sulfide compound. For the aryl compounds, though, there was a much smaller potential difference between the aryl sulfides and selenides $1150 \mathrm{mV}$ decrease in going from 1,1'-thiobis(benzene) to 1,1'-selenobis(benzene)]. These differences may explain some of the electrochernical differences between the aryl

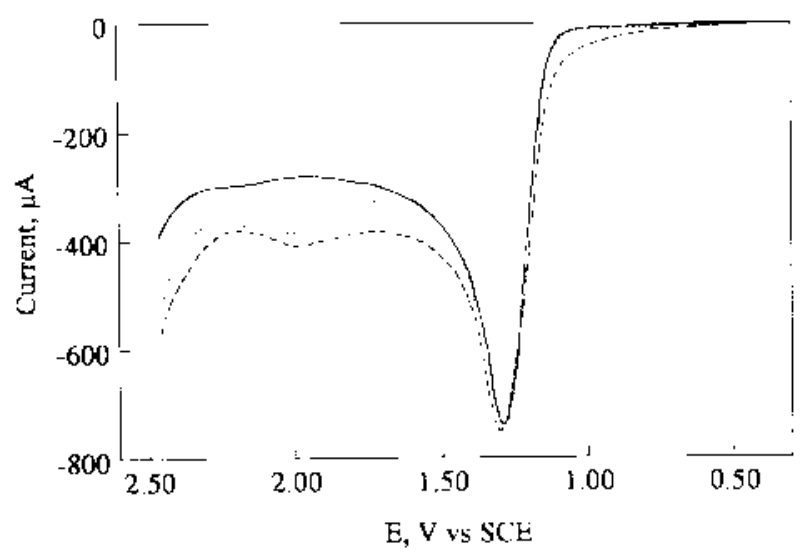

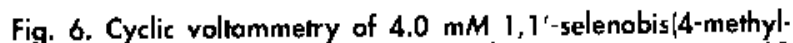
benzene) in acetonitrile at a platinum electrode, scan rate: 100 $\mathrm{mV} / \mathrm{s}, 0.10 \mathrm{M}$ sodium perchlorate. (-) Experimental cyclic voltammogam in the absense of 2,6-di- - bulyl pyridine. $1--1$ Experimental cyclic voltammogram in the presence of $6.0 \mathrm{mM} \mathrm{2,6-}$ di-^butyl pyridine. (…) Synthetic cyclic voltrmmogram abtained by adding the voltammogram for $4.0 \mathrm{mM} 1,1^{\prime}$-selenobis $[4$-melhylben. zene) to the valtammogram of $2.0 \mathrm{mM} 1,1^{\prime}$-seleninylbis(4-meihylbenzene). sulfides and selenides. 'The oxidation of 1,1'-thiobis(benzene) is thought to take place at the aromatic ring, leading to the rapid loss of $\mathrm{H}^{-}$, and the formation of the sulfonium product. In contrast, in the selenium analogue, the oxidation is mostly on the selenium atom, leading to the rapid reaction with water and the primary formation of the selenoxide. Thus, in the former case, we are observing mostly the oxidation of the aromatic ring, the potential of which has been lowered by the inductive and resonance effects of a neighboring sulfur. In the latter case, the oxidation takes place at the selenium atom, as indicated by the predominant formation of the selenoxide. If the ring were not oxidized in the sulfur analogues, the sulfur itself would have been oxidized at a much higher potential. These differences lead to a reversal in trends between the aryl and alkyl sulfides and selenides. In the former case, the aryl sulfides $(+1.56 \mathrm{~V})$ are easier to oxidize than the alkyl sulfides $(+1.72$ to $+1.80 \mathrm{~V})$, while in the latter case, the aryl selenides $(: 1.41 \mathrm{~V})$ are harder to oxidize than the alkyl selenides $(11.14$ to $+1.33 \mathrm{~V})$.

\section{Conclusions}

The isolated product of the oxidation of diaryl selerides leads primarily to diaryl selenoxides. The diaryl selenoxides, which ean be further uxidized, were not observed in the cyelic voltammetry due to two processes. The first is that the acid generated by the formation of the selenoxide protonated this species, making the oxidation very difficult. For the 4-methyl derivative, the addition of a nonnucleophilic base led to the appearance of the selenoxide peak. Lnder the same conditions, the seleroxide peak was not observed for diphenyl selenide. By trapping any hydroxyl product with trimethyl oxonium ion, the initial product, the hydrate of the selenoxide, was observed using ${ }^{1} \mathrm{H}$ and ${ }^{3} \mathrm{C} \mathrm{NMR}$ spectroscopy. The diaryl selernoxide, that was formed by the oxidation of the diaryl selenide, was considerably more basic than the corresponding sulfoxide Protonation of the diaryl selenoxide occurred readily in the presence of a strong acid, and further oxidation of the conjugate acid was not observed.

\section{Acknowledgment}

The authors would like to atknowledge the help of Sheldon Cremer for help in the ${ }^{1} \mathrm{H}$ and ${ }^{i} \mathrm{C}$ NMR spectra and for providing the trimethyloxonium tetrafluoroborate.

Manuscript submitted March 11, 1996; revised manuscript received March 1, 1997

Marquette Iniversity assisted in meeting the publication costs of this article

\section{REFERHNCES}

1. M. Filinson and J. Simonet, J. Electroanal. Chem., 336, 363 (1992)

2. P. T. Cottrell and C. K. Mann, This Juurnat, 116, 1499 (1969).

3. W. K. Musker, Acc. Chem. Res., 13, 200 (1980)

4. G. S Wilson D. D. Swanson, J. T. Klug, R. S. Glass, M.D. Ryar, and W. K. Musker, $J$ Am. Chem. Soc, $101,1040(1979)$

5. H. Fujihara, R. Akaishi, and N. Fukukawa, Chem. L,ett., $549(1990)$

6. II. Fujihara, A. Nakamura, R. Akaishi, and $\mathrm{V}$. Furukawa ibid, 393 (1990).

7 H Fujihara, M. Yabe J.-J. Chiu, and V. Furukawa, Tetrahedron Lett., 32, 4345 (1991)

8. S. Torii, Y. Matsuyama, K. Kawasaki, and K. Lnevama, Bull. Chem. Suc. Jpn, 46, 2912 (1973).

9. K. Uneyama and S. Torii, J. Org. Chem, 37, 367 (1972).

10. F. Magno and G. Bontempelli, $J$. Electroanal Chem., $36,389(1972)$

11. R. Seeber, A. Cinquantini, P. Zanello, and G. A. Mazzocchin, ibid., 88, 137 (1978)

12. H. Behret and G. Sandstede, ibid, 56, 455 (1974).

13. K. Uneyama and S. Torii: Tetrahedron Lett., 323 (1971)

14. B. Dakova, 1. Lamberts, and M. Evers, Electrochim. Acta, 39, 2363 (1994).

15. V. Jouikov, V. Ivkov and D. Fattahova, Tetrahedron 
Lett., 34, 6045 (1993).

16. T. FIashimoto, M. Sugita, H. Kitano, and K. Fukui, Nippon Kagaku Zasshi, 88, 991 (1967).

17. M. R. Detty, J. Org. Chem., 45, 274 (1980)

18. R. Paetzold and U. Lindner, Z. Anorg. Allg. Chem., 350, 295 (1967).

19. J. D. McCullough and N. W. Tideswell, I. Am. Chem. Soc, 76, 3091 (1954).

20. D. S. Polcyn and I. Shain, Anal. Chem., 38, 370 (1966).

21. N. Furukawa, S. Ogawa, K. Matsumura, and FL Fujihara, J. Org. Chem, 56, 6341 (1991).

22. W. Nakanishi and Y. Ikeda, Bull. Chem. Soc. Jpn., 56, 1661 (1983).

23. R. S. Nicholson and I. Shain, Anal. Chem., 36, 706 (1964).
24. G. Bontempelli, F. Magno, G.-A. Mazzocchin, and R. Secber, J. Electroanal. Chem., 55, 109 (1974).

25. L. Engman, C. M. P'ersson, C. M. Andersson, and M. Berglund, J. Chem. Soc, Perkin Trans, 2, 1309 (1992).

26. D. Hadzi, C. Klofutar, and S. Oblak, J. Chem. Soc. (A), 905 (1968).

27. C. Klofutar, F. Krasovec, and M. Kusar, Croat. Chem. Acta, 40, 23 (1968).

28. K. B. Sharpless, M. W. Young, and R. P. Lauer, Tetrahedron Lett., 1979 (1973).

29. M. R. Detty, A. E. Friedman, and A. R. Oseroff, J. Org. Chem., 59, 8245 (1994).

30. V. V. Florn and R. Paetzold, Z. Anorg. Allg. Chem, 398, $179(1973)$. 